\title{
Educational Mismatch and Labour Mobility of People with Disabilities: The Spanish Case
}

\author{
Maite Blázquez * and Miguel A. Malo ${ }^{\dagger, 1}$ \\ * Universidad Autónoma de Madrid, Spain. ${ }^{\dagger}$ Universidad de Salamanca, Spain
}

Received 25 February 2005; accepted 7 October 2005

\begin{abstract}
In this paper we analyze the job-matching quality of people with disabilities. We do not find evidence of a greater importance of over-education in this group in comparison to the rest of the population. We find that people with disabilities have a lower probability of being over-educated for a period of 3 or more years, a higher probability of leaving mismatch towards inactivity or marginal employment, a lower probability of leaving mismatch towards a better match, and a higher probability of employment mobility towards inactivity or marginal employment. The empirical analysis is based on Spanish data from the European Community Household Panel from 1995 to 2000.
\end{abstract}

Keywords: Mismatch, disability, over-education, under-education, mobility, discrimination, over-qualification

JEL Classification: I29, I12, J41, J62, J71

\section{Introduction}

Since the seminal work of Freeman (1976), the literature on overeducation and under-education has grown rapidly as shown in Sloane's overview (2004). Educational mismatch has been analysed from a variety of perspectives such as career mobility, educational returns, the quality of the match between jobs and workers, etc. One of the least dealt with approaches is the analysis of specific population groups. Here, we will focus on one specific group in a disadvantaged position in the labour

\footnotetext{
1 Author for correspondence: malo@usal.es. We would like to thank Delia Dávila and an anonymous referee for their helpful comments to a previous version of this paper. The bulk of this research was carried out when Maite Blázquez was member of the CentrA Foundation (Spain). Miguel A. Malo acknowledges the financial support received from the 'Junta de Castilla y León' (research project SA092/02). The usual disclaimer applies.
}

(C) Revista de Economía Laboral 
market: people with disabilities. We will analyse not only the extent of educational mismatch in this collective, but also whether disability affects the educational mismatch, the temporal persistence of this mismatch, the mobility towards a better match, and the employment mobility in general (discounting the possible influence of educational mismatch on this type of mobility).

Disadvantaged groups (because of discrimination, for example) find it more difficult to compete in the labour market, and educational mismatch may be one consequence of this. Despite the legal normative in Spain which gives disabled people some "advantages" in obtaining access to the labour market ${ }^{2}$, people with disabilities, either mental or physical, are still especially affected by discrimination based on prejudices and lack of accurate information in the rest of society regarding impairments and their consequences. Furthermore, we know that different disabilities are related to different levels and types of prejudices, as Baldwin and Johnson (1995) discuss in terms of the labour market discrimination suffered by people with disabilities. Therefore, the case of people with disabilities is potentially interesting as it shows how education and skills are related to job requirements when individuals are in a weaker situation in the labour market.

Previous studies (Dean and Dolan, 1992; Hendricks et al., 1997) show that people with disabilities exhibit higher rates of return from tertiary education. Nonetheless, the international evidence (Zwinkles, 2001) reveals that disabled people present lower educational attainments compared with the rest of society. The lower educational level of this group might decrease the likelihood of suffering an educational mismatch in a job. Therefore, it is an empirical issue to show whether people with disabilities tend to be more likely to be mismatched, as observed among other disadvantaged groups (such as women and ethnic minorities) or, in contrast, they exhibit a lower probability of being mismatched.

When analyzing the incidence of educational mismatch among people with disabilities, a labour mobility analysis is of paramount importance. It turns out that disadvantaged groups in the labour market might experience a higher mobility outside of the labour market. And when these groups are initially mismatched, making job-to-job transitions would not help to improve the job match.

2 The legal protection of people with disabilities is developed in the article 38.1 of the 13/1982 Act about Social Integration of People with Disabilities, the 66/1997 Act and the article 1.2 of the Royal Decree 27/2000 on the quota system in the private and public sectors (recently updated in 2000). For the legal details, see for example, Sánchez-Cervera and Sánchez Cervera (2000). 
For our purpose, we use Spanish data from the European Community Household Panel (ECHP), which includes information on educational mismatch and disability. As we will explain later, we restrict ourselves to the period 1995-2000. The main reason for this is to use homogeneous information related to disability. Moreover, this data base allows us to distinguish different types of educational mismatch: first, over-education or over-qualification, and, second, educational mismatch in a broad sense (over-education, under-education or 'horizontal' mismatch). The use of these two different definitions of educational mismatch will provide a much richer analysis. Finally, as the data base is a panel we will be able to check the persistence of the different types of mismatch.

The main results are the following: People with disabilities have a lower probability of being over-educated for a period of 3 or more years; a higher probability of leaving a labour mismatch in a broad sense, or merely moving from over-education towards inactivity or marginal employment; a lower probability of leaving mismatch in a broad sense towards a better match; and a higher probability of employment mobility towards inactivity or marginal employment.

The remainder of the paper is as follows. In the next section, we review previous literature about the educational mismatch of disadvantaged groups. In the third section, we present the empirical analysis in three parts. First, we describe the data base and we define the main variables, educational mismatch and disability. Second, the descriptive analysis shows the main characteristics of the data, and the most important features of educational mismatch with regard to people with disabilities. Third, the econometric analysis includes different multinomial logit models to find out the determinants of the persistence of mismatch, mobility improving job matching and employment mobility in general. A final section summarises the main conclusions of the article.

\section{Background}

Disadvantaged groups experience a weaker position in different aspects of their participation in the labour market compared to the average attainments of all individuals. Presumably this weaker position could affect the quality of the job matching for these groups. To our knowledge, literature on mismatch has analysed two disadvantaged collectives: ethnic minorities and women.

Battu and Sloane (2002) have analysed the case of ethnic minorities in Britain, finding that non-whites have a higher probability of being over-educated. This difference could be explained by discrimination 
and/or spatial constraints. On one hand, some employers may only hire members of ethnic minorities who posses higher educational levels or qualifications than whites for the same job. On the other hand, commuting is harder for isolated ethnic communities, and it reduces the probability of a better match (increasing the probability of having educational mismatch).

Concerning females, Frank (1978) presents a theory of differential over-education by gender. Women who live with a partner will have a higher probability of being over-educated because their job search is conditioned by the job search of their spouses. As men usually enjoy higher wages, the family will try to optimise the quality of the job match of males, while the job search of females will be optimally subject to the previous optimisation. The result is that these women have a job search spatially constrained to the territory where their spouses have their jobs. Therefore, these women will have a higher probability of being overeducated. Frank (1978) offers empirical evidence supporting his theory and McGlodrick and Robst (1996) present an opposing result using a different data base.

Presumably, the educational mismatch of people with disabilities will have some of the characteristics of the problems described for the other groups, but with new aspects. There is previous literature confirming that labour market discrimination exists for people with disabilities. Among different types of discrimination, wage discrimination is perhaps the most studied. For example, Baldwin and Johnson (1995) find that there is a large difference between the employment rate of disabled and non-disabled women, but only a small part of the differential is attributable to wage discrimination. However, we should consider that disability is not only a feature potentially related to discrimination, but to lower productivity as well. Therefore, an educational mismatch can exist not only because of discrimination but also as a form of compensation for lower productivity. In addition, the extent of the educational mismatch might be potentially related to the behaviour of people with disabilities concerning investment in education. A 'stylised fact' at the international level is the relatively lower educational level of people with disabilities, especially in Spain and other southern European countries (GarcíaSerrano and $\mathrm{Malo}^{3}$, 2002; Malo, 2003). At first sight, this is paradoxical because the scarce literature regarding the effect of education on the labour market performance of people with disabilities remarks on the advantages of reaching higher educational levels (Dean and Dolan, 1992; Hendricks et al., 1997). However, a lower investment in education might

\footnotetext{
3 This article is based on a wider report (in English) available upon request.
} 
be rational if people with disabilities anticipate lower returns with respect to the rest of the population for the same educational levels, or if the educational system is not adapted to the special requirements of different types of disabilities. In addition, we have to consider that the allocation of time is affected by disability, mainly because disability is a characteristic which 'steals' time (Oi, 1991). This negative effect of disability on time budgets of individuals has two dimensions. On one hand, the relative valuation of long-term investments in education can be severely affected by disability. Obviously, this effect will be different for people who become disabled after their entry into the labour market than for those who are disabled before 4 . On the other hand, the amount of time available for commuting will be lower and, therefore, it potentially increases the probability of being mismatched.

Another interesting issue is the relationship between mismatch and mobility, and how disability could affect this relationship. In the literature we can find different points of view about the relationship between over-education and mobility. From the standpoint of the neoclassical theory, an unordered increase in the number of people investing in higher education prompts firms and workers to adjust their educational requirements and their investments in education respectively, so that over-education will be no more than a short-term problem. Matching theory (Jovanovic, 1979) also supports the view that overeducation is a temporary phenomenon. Over-education is a poor match for workers. Over time, however, workers are expected to improve their job match and over-education will be temporary. Another theory which approaches over-education as a short-term problem is the occupational mobility theory (Rosen, 1972; Sicherman and Galor, 1990) which states that over-education is a temporary problem because over-educated workers will move towards better jobs (inside or outside the firm) in order to enjoy a higher quality job match and, ceteris paribus, higher wages.

However, other theories consider over-education as a more serious and long-lasting problem. In Spence's job screening model (1973) the uncertainty surrounding the hiring decision leads individuals to invest in education in order to signal high productivity. Job competition theory (Thurow, 1975) also views over-education as a rather permanent phenomenon. In this model, the labour market is characterized by a queue of workers, with those at the head of the queue being hired first. A worker's position in the queue is determined by their costs for the firm in

\footnotetext{
4 In our data base, we only have information about the current disability status of interviewees, but not the date of the beginning of their disability or functional limitation.
} 
terms of training. If education is a proxy for training costs then, highly educated workers would require less training. In this model, however, productivity and wages are fixed in relation to jobs, so that over-educated workers have identical productivity and receive the same wages as those who are in jobs with the required level of education.

Presumably, this sort of mobility to improve job match is related to individual characteristics, for example, disability. If people with disabilities suffer discrimination and/or mismatch as a sort of compensation for the low productivity related to disability, they will have a lower probability of moving towards a job with a better match. If this is the case then, skill mismatch could be a more serious and long-lasting problem for this group of people.

\section{Empirical analysis}

\subsection{Data base and definitions of main variables}

The ECHP is a household panel survey promoted by EUROSTAT. This data base is suitable for our analysis because it includes information on disability and educational mismatch. The first year of this survey was 1994. Nonetheless, we will use the Spanish data for the period 1995-2000 for two reasons: the questions on disability were changed slightly in 1995, and the type of contract (temporary and permanent) is available from 1995 onwards. This data base has been used before to analyse educational mismatch in Spain, for example by Alba-Ramírez and Blázquez (2004) 5 .

In general, we can distinguish two main types of definitions for educational mismatch: "objective" and "subjective" definitions. The subjective definitions are based on individual workers' self-reports on their level of skill utilisation. Each worker is asked directly whether he/she is over-educated or under-educated for the workhe/she does, or he/she is asked what minimum education is required for their job. The self-reported level of required education is then compared to the worker's actual educational level to assess the job match. Many papers in the literature of over-education have used a subjective definition (Duncan and Hoffman, 1981; Sicherman, 1991; Cohn and Kahn, 1995; Rumberger, 1987; Hartog and Oosterbeek, 1988; Alba-Ramírez, 1993). The objective definitions can also be classified into two types. In the first type, educational mismatch is assessed by comparing years of education with the average educational level in the worker's current occupation. Workers are classified as overeducated if they have more than the average years of education for their

\footnotetext{
${ }^{5}$ Previous works analysing educational mismatch in Spain with other data bases are, among others, Alba-Ramírez (1993) and García-Serrano and Malo (1996).
} 
occupation, plus one standard deviation (Verdugo and Verdugo, 1989; Groot and Maassen van den Brink, 1997). In the second type, educational mismatch is defined by comparing the current educational level and the job-level requirements (Thurow and Lucas, 1972; Hartog and Osterbeek, 1988).

Although the ECHP does not provide direct information on the educational requirements of jobs, it contains several questions that provide us with enough information to assess the type of job match from a subjective perspective. Workers are allocated different types of job match according to their responses to the following three questions:

1. Do you feel you have skills or qualifications to do a more demanding job than the one you have now? The possible answers are 'yes' and 'no'.

2. Have you had formal training or education that has given you the skills needed for your present type of job? The possible answers are 'yes' and 'no'.

3. How much has this training or education contributed to your present job? The answers are 'a lot', 'a fair amount', 'not very much', and 'not at all'. Only those individuals answering 'yes' to the previous questions are asked this third question.

The response to the first question provides us with the first definition of educational mismatch. People reporting that they have the skills or qualifications to do a more demanding job will have an educational mismatch related to over-education or over-qualification. We will call it mismatch type A.

The two following questions are used to obtain an additional definition of mismatch. We define mismatch type B for those who answer 'no' to the second question and those who answer 'yes' to the second question but 'not very much' or 'not at all' in the third question ${ }^{6}$. The scope of this definition is very wide because it includes under-educated workers and /or people having the job educational requirements but not the specific field of education required by the job ${ }^{7}$. Therefore using these two definitions we will have a richer empirical analysis focusing on different aspects of the job match quality.

\footnotetext{
${ }^{6}$ We also tried with an alternative definition (mismatch type C) which included people answering "yes" to the second question and "not very much" or "not at all" to the third question. The estimation results in this case are not significant in most of the cases, and when significant, they are very similar to the other two cases.

7 For example, in the Spanish Public Administration a significant majority of jobs are defined in terms of educational level (primary, secondary or university level) but not in terms of specialization fields, for example for the university level it is not specified whether the degree is in Economics, Sociology, Education, etc.
} 
To sum up, mismatch type A represents over-education or overqualification, and type B is mismatch in general (over-, under-education or horizontal mismatch).

Now, we proceed to describe the variables related to disability. The questions about disability are the following:

Q158: Do you have any chronic physical or mental health problem, illness or disability? If Yes $\rightarrow$ Q159

Q159: Are you hampered in your daily activities by this chronic or mental health problem, illness or disability?

Yes, severely / Yes, to some extend / No

Those who answer 'yes' (severely or to some extent) can be defined as people with disabilities (either mental or physical). Of course, this is a self-evaluation and it does not refer to an 'objective' definition of disability. Nevertheless, it provides a useful approach to measuring the selfperceived disability. The initial filtering question was added in the second wave (1995). In order to avoid any problems related to this change in the questionnaire, we will only use data from 1995.

We would like to point out the two main characteristics of the disability definition included in the ECHP:

- It is not exactly correspondent with the international definition provided by the World Health Organization (WHO), and, therefore, there is a lack of comparability with other international surveys on disability.

- It is not correspondent with the administrative definitions, which are mainly 'work disability'. In fact, this is a positive characteristic, because it means that the ECHP definition is not far from the WHO definition, which defines disability with respect to daily activities.

Therefore, the figures obtained from the ECHP give an approximation of the phenomenon of disability, and though not strictly comparable with other data sources designed to follow the international definitions of disability, they are closer to them than any sort of administrative data (which usually focuses strictly on disability with respect to work).

Although the questionnaire allows us to define two subtypes of disability (severely hampered, and only hampered to some extent), we will use only one category which consists of the aggregation of both subtypes of disability. The main reason is that the subtypes do not correspond to any standard subgroups of the WHO definition of disability. The main effect of this aggregation is that we will have a disabled population with a greater 
heterogeneity than in other definitions (especially with respect to the administrative definitions) ${ }^{8}$.

\subsection{Descriptive analysis}

In this section we provide the main characteristics of the selected sample. We select a sample of wage and salary workers aged between 16 and 65 years old and working more than 15 hours per week, so that self-employed and unpaid family-employed workers are not included. Table 1 contains some descriptive statistics (mean and standard deviation) for two alternative definitions of educational mismatch. The variables, used as explanatory variables in the rest of the analysis, relate to personal and job characteristics: sex, marital status, age, educational attainments, training, type of contract, type of firm, and seniority in current job. The descriptive analysis is made for the total sample, and separately for people with and without disabilities.

The prevalence ratio reported in Table 1 is $4 \%$, very close to the ratio estimated for 1999 with the Encuesta sobre Discapacidades, Deficiencias y Estado de Salud (5\% for people aged between 16 and 64 years old) ${ }^{8}$. Thus, although the disability definition included in the ECHP is not exactly correspondent with the international definition provided by the WHO, it provides a good approximation.

The results reported in Table 1 reveal that people with disabilities tend to be older. It would be expected, therefore, that these people exhibit lower educational levels and lower labour mobility. In fact, when comparing people with and without disabilities, we can observe clear differences in the sample means. People with disabilities tend to be older (around 44 years old on average, in contrast to 37 years old for the group of people without disabilities) and with lower educational attainments (70\% of people with disabilities report having just their primary education completed, while the percentage of people without disabilities reporting a lower secondary education diploma as the maximum educational level completed, is around 46\%). This low educational level is consistent with the 'stylised facts' on disability in Spain (see Malo, 2003) and the European Union (see García-Serrano and Malo, 2002). The reported results also reveal that people with disabilities are less likely to receive onthe-job training provided by the employer.

${ }^{8}$ Although it is potentially very interesting, we have not considered the information included in the ECHP on disability pensions, because they are mixed with short-term sickness benefits and, therefore, it would be not suitable for our analysis. About disability pensions in Spain see, for example, Roqueta (2000).

${ }^{8}$ See Malo (2003). 
Table 1. Means and standard deviations (in italics).

\begin{tabular}{|c|c|c|c|}
\hline Variable & $\begin{array}{c}\text { All } \\
(\mathrm{N}=\mathbf{2 0 , 6 3 1 )}\end{array}$ & $\begin{array}{c}\text { People without } \\
\text { disabilities }(\mathrm{N}=19,814)\end{array}$ & $\begin{array}{c}\text { People with disabilities } \\
\qquad(\mathrm{N}=817)\end{array}$ \\
\hline \multirow[t]{2}{*}{ Male } & 0.642 & 0.643 & 0.614 \\
\hline & 0.479 & 0.479 & 0.488 \\
\hline \multirow{2}{*}{ Married } & 0.626 & 0.623 & 0.714 \\
\hline & 0.483 & 0.484 & 0.451 \\
\hline \multirow[t]{2}{*}{ Age } & 38.0 & 37.7 & 44.3 \\
\hline & 10.9 & 10.8 & 11.2 \\
\hline \multicolumn{4}{|l|}{ Educational. Level } \\
\hline \multirow[t]{2}{*}{ Primary } & 0.472 & 0.462 & 0.701 \\
\hline & 0.498 & 0.498 & 0.459 \\
\hline \multirow[t]{2}{*}{ Second. } & 0.210 & 0.213 & 0.149 \\
\hline & 0.407 & 0.409 & 0.357 \\
\hline \multirow{2}{*}{ University } & 0.318 & 0.325 & 0.149 \\
\hline & 0.465 & 0.467 & 0.357 \\
\hline \multirow[t]{2}{*}{ Training } & 0.322 & 0.326 & 0.239 \\
\hline & 0.467 & 0.468 & 0.426 \\
\hline \multirow{2}{*}{ Open-ended contract } & 0.662 & 0.662 & 0.656 \\
\hline & 0.472 & 0.472 & 0.476 \\
\hline \multirow[t]{2}{*}{ Mismatch Type A } & 0.571 & 0.577 & 0.437 \\
\hline & 0.494 & 0.494 & 0.497 \\
\hline \multirow{2}{*}{ Mismatch Type B } & 0.570 & 0.565 & 0.706 \\
\hline & 0.495 & 0.496 & 0.456 \\
\hline \multicolumn{4}{|l|}{ Type of firm } \\
\hline \multirow[t]{2}{*}{ Pub.Adm./Pub. Firm } & 0.263 & 0.264 & 0.257 \\
\hline & 0.440 & 0.440 & 0.433 \\
\hline \multirow[t]{2}{*}{ Private $(<20)$} & 0.366 & 0.365 & 0.392 \\
\hline & 0.482 & 0.481 & 0.488 \\
\hline \multirow[t]{2}{*}{ Private (20-500) } & 0.289 & 0.289 & 0.279 \\
\hline & 0.452 & 0.453 & 0.449 \\
\hline \multirow[t]{2}{*}{ Private $(>500)$} & 0.082 & 0.082 & 0.072 \\
\hline & 0.273 & 0.274 & 0.259 \\
\hline \multicolumn{4}{|l|}{ Seniority } \\
\hline \multirow[t]{2}{*}{$<1$ year } & 0.217 & 0.218 & 0.206 \\
\hline & 0.408 & 0.409 & 0.399 \\
\hline \multirow[t]{2}{*}{$1-5$ years } & 0.284 & 0.286 & 0.248 \\
\hline & 0.450 & 0.451 & 0.432 \\
\hline \multirow[t]{2}{*}{ 5-10 years } & 0.134 & 0.134 & 0.129 \\
\hline & 0.339 & 0.340 & 0.335 \\
\hline \multirow{2}{*}{$>10$ years } & 0.365 & 0.363 & 0.417 \\
\hline & 0.480 & 0.480 & 0.490 \\
\hline \multirow[t]{2}{*}{ Disability } & 0.040 & & \\
\hline & 0.195 & & \\
\hline
\end{tabular}

Source: ECHP1995-2000 (Spain).

Note: To estimate means we proceed as follows: mean $($ age $)=(\mathrm{N} 95 / \mathrm{N}) * \mathrm{~m} 95+(\mathrm{N} 96 / \mathrm{N}) * \mathrm{~m} 96+$ $(\mathrm{N} 97 / \mathrm{N}) * \mathrm{~m} 97+(\mathrm{N} 98 / \mathrm{N}) * \mathrm{~m} 98+(\mathrm{N} 99 / \mathrm{N}) * \mathrm{~m} 99+(\mathrm{N} 00 / \mathrm{N}) * \mathrm{~m} 00$. Where $\mathrm{m} 95 \ldots \mathrm{m} 00$ denote the means of the variable "age" for each year, N95...N00 the number of observations from 19952000 , and $\mathrm{N}=\mathrm{N} 95+\ldots+\mathrm{N} 00$. The same criteria are applied for the standard deviations and for the rest of the explanatory variables. 
Regarding job characteristics, we find that the percentage of people with disabilities working in private firms with fewer than 20 employees is slightly higher than the corresponding percentage in the group of people without disabilities. In contrast, people without disabilities are more likely to work in the public sector and private firms with more than 20 employees. Finally, the descriptive analysis reveals that people with disabilities tend to exhibit longer durations in their current job than those people without disabilities.

As regards the incidence of educational mismatch, we can also appreciate clear differences depending on the definition of educational mismatch. People with disabilities are clearly more likely to suffer a mismatch type B. More than $70 \%$ of this group of people report being in such a situation, in contrast to $56.5 \%$ corresponding to the group of people without disabilities. Nonetheless, we obtain the opposite result when using mismatch type A definition. In this case the percentage of people with disabilities who report being mismatched is around $44 \%$, while the corresponding percentage among the group of people without disabilities is around $58 \%$.

Table 2. Distributions of disability and mobility of mismatched individuals towards a better match or other situation (percentages).

\begin{tabular}{|c|c|c|c|}
\hline \multicolumn{4}{|c|}{ MISMATCH TYPE A } \\
\hline \multicolumn{4}{|c|}{ Mobility } \\
\hline & W/O disab. & W. disab. & Total \\
\hline $\mathrm{z}=0$ & 40.39 & 20.37 & 759 \\
\hline $\mathrm{z}=1$ & 36.61 & 37.04 & 698 \\
\hline $\mathrm{z}=2$ & 23 & 49.59 & 449 \\
\hline Total & 100 & 100 & 1,906 \\
\hline \multicolumn{4}{|c|}{ MISMATCH TYPE B } \\
\hline & W/O disab. & W. disab. & Total \\
\hline $\mathrm{z}=0$ & 36.1 & 35.78 & 749 \\
\hline $\mathrm{z}=1$ & 36.96 & 16.51 & 745 \\
\hline $\mathrm{z}=2$ & 26.94 & 47.71 & 582 \\
\hline Total & 100 & 100 & 2,076 \\
\hline
\end{tabular}

Source: ECHP1995-2000 (Spain).

$\mathrm{z}=0$ if individual remains mismatched.

$\mathrm{Z}=1$ if individual goes towards a better matching.

$\mathrm{Z}=2$ if individual goes towards other situations.

Table 2 shows the distribution of disability and mobility of mismatched individuals (definitions type A and B). For both definitions we see that the mobility of people with disabilities towards inactivity or 
marginal employment is double (almost $50 \%$ ) that of people without disabilities (around $25 \%$ ). The mobility towards a better match (a reduction of educational mismatch) is different considering both definitions of mismatch. For mismatch type B (general mismatch) only $16.5 \%$ of people with disabilities move towards a better match, while for people without disabilities this percentage goes to 37. For mismatch type A (over-education), this percentage is almost the same for both groups (37.0 and 36.6 respectively). These differences between the two definitions of educational mismatch will be explained with more detail in the econometric analysis.

To sum up, we see that people with disabilities do not tend to have higher educational levels in order to 'compensate' for their disabilities. Considering educational mismatch, the descriptive analysis shows that people with disabilities have lower levels of mismatch type A (overeducation) but higher levels of mismatch type B (mismatch in a broad sense). Moreover, we have seen that mobility from mismatch towards inactivity or marginal employment is much higher for people with disabilities than for people without them. However, mobility towards a better match presents no difference when considering disability for overeducation (mismatch type A), but it is substantially different considering mismatch in a broad sense (type B) in contrast to people with disabilities.

\subsection{Econometric analysis}

The aim of this section is twofold. First, we analyse the determinants of educational mismatch and its persistence using alternative definitions. Second, we analyse the relationship between mobility and educational mismatch under two directives: mobility towards a better job match, and job mobility in a broad sense. For both purposes we use a longitudinal analysis based on information from the ECHP 1995-2000, with 20.85\%, $19.35 \%$ and $59.75 \%$ of people observed during one, two or more than two years respectively.

In order to achieve the first goal we estimate a multinomial logit model for each definition of educational mismatch. The selected sample for this analysis consists of wage and salary workers aged between 16 and 65 years old and working more than 15 hours per week. The multinomial logit regressions results are given in Tables 3 and 4, where the dependent variable is a four point variable indicating the persistence of educational mismatch. The variable takes value 0 if, in each year the individual is observed, he/she reports not suffering an educational mismatch; 1 if the individual reports being mismatched for one year; value 2 if the individual has experienced an educational mismatch for two years; and value 3 if the 
duration of the educational mismatch is longer than two years ${ }^{9}$. For each definition of educational mismatch, three set of coefficients are estimated $^{10}$. From these three sets of coefficients, we can calculate the probability that an individual experiences an educational mismatch for one, two, or more than two years, conditional on a vector of explanatory variables that includes personal and job characteristics. To better understand the results, we present them in terms of the relative risk ratios (RRR) instead of the coefficients. For instance, an individual who only differs from the reference in that he/she has a university educational level instead of primary level has twice the probability of being mismatched in 1 wave (exactly 2.25). When the RRR is lower than 1 the interpretation is the following: for example, an individual who only differs from the reference in that he/she is disabled has a probability of being mismatched 3 or more waves nearly two times $(1.96=1 / 0.509)$ lower than those who are not disabled ${ }^{11}$.

It is worth mentioning that, independent of the definition of educational mismatch, there is no evidence of people with disabilities exhibiting either higher or lower probabilities of being mismatched, with the only exception of the lower probability of being over-educated for 3 or more waves shown in Table 3. In this sense we can not say, therefore, that people with disabilities experience a weaker position in the labour market ${ }^{12}$. Thus, we find a pattern of educational mismatch for people with disabilities different from that of other disadvantaged groups in the labour market such as ethnic minorities (Battu and Sloane, 2002) or women who exhibit higher levels of over-education (Frank, 1978). Nonetheless, as we will argue later, the weaker situation of people with disabilities will be clear when we analyse the determinants of the probability of moving from a mismatch towards a better job match and the determinants of the probability of employment mobility in general.

For the rest of the variables, there are clear differences in their distributions depending on the definition of educational mismatch. For types A (over-qualification) and B (mismatch including under-education), we find males to be more likely than females to experience an educational mismatch in a persistent way. For the two definitions, we also find that the probability of being mismatched increases with age, in a non-linear

\footnotetext{
9 These two last categories also include individuals who suffered educational mismatch during several non-consecutive years.

10 People who report not being mismatched are the omitted category.

11 Therefore, when the coefficient is negative (see the sign of the t statistic) the best way to compare results is dividing 1 by the RRR shown in the tables.

12 This result is in contrast to the one obtained by Battu and Sloane (2002) regarding ethnic minorities in Britain.
} 
way, only for long-lasting mismatch (2, 3 or more waves). This last result seems to contradict partially the predictions of the occupational mobility theory. Under this theory, over-education would be part of a career path or insertion process in the labour market, so that we would expect that younger workers are more likely to be over-educated. Thus, our results reveal that over-education (and skill-mismatch in general) could be a more serious and long-lasting problem, at least in the Spanish economy.

Table 3. Multinomial logit model on the probability of having over-education (mismatch type A). ECHP 1995-2000 (Spain).

\begin{tabular}{|c|c|c|c|c|c|c|}
\hline \multirow{3}{*}{ Variables } & \multirow{2}{*}{$\ln \left[\frac{\mathrm{P}}{\mathrm{P}}\right.$} & \multirow{2}{*}{$\frac{\operatorname{Pr}(y=1)}{\operatorname{Pr}(y=0)}$} & \multirow{2}{*}{\multicolumn{2}{|c|}{$\left[\frac{\operatorname{Pr}(y=2)}{\operatorname{Pr}(y=0)}\right]$}} & \multirow{2}{*}{\multicolumn{2}{|c|}{$\left[\frac{\operatorname{Pr}(y=3)}{\operatorname{Pr}(y=0)}\right]$}} \\
\hline & & & & & & \\
\hline & RRR & $\mathrm{t}$ & RRR & $\mathrm{t}$ & RRR & $\mathrm{T}$ \\
\hline Male & 1.155 & 1.36 & 1.584 & 4.11 & 1.463 & 3.74 \\
\hline Married & 0.877 & -0.92 & 0.968 & -0.15 & 1.146 & 1.22 \\
\hline Age & 1.048 & 1.41 & 1.048 & 1.30 & 1.126 & 3.72 \\
\hline $\mathrm{Age}^{2}$ & 0.999 & -1.63 & 0.999 & -1.95 & 0.998 & -4.87 \\
\hline \multicolumn{7}{|l|}{ Educational Level } \\
\hline Primary & - & - & - & - & - & - \\
\hline Secondary & 2.261 & 6.08 & 2.885 & 7.51 & 3.400 & 9.21 \\
\hline University & 2.252 & 5.29 & 2.981 & 6.77 & 4.058 & 9.24 \\
\hline Training & 1.080 & 0.63 & 1.271 & 1.97 & 1.465 & 3.40 \\
\hline Open-ended contract & 1.167 & 1.23 & 1.126 & 0.75 & 1.223 & 1.67 \\
\hline Disability & 0.764 & -1.43 & 0.846 & -0.82 & 0.509 & -2.94 \\
\hline \multicolumn{7}{|l|}{ Tipe of Firm } \\
\hline Pub. Adm. and Pub. Firm & 0.884 & -0.70 & 1.022 & 0.25 & 1.283 & 1.77 \\
\hline Private (<20 workers) & - & - & - & - & - & - \\
\hline Private $(20-500$ w.) & 0.867 & -1.40 & 0.969 & -0.47 & 1.198 & 1.44 \\
\hline Private (>500 w.) & 0.732 & -1.53 & 0.642 & -2.24 & 1.037 & 0.17 \\
\hline \multicolumn{7}{|l|}{ Seniority } \\
\hline$<1$ year & - & - & - & - & - & - \\
\hline $1-5$ years & 0.885 & -0.89 & 1.197 & 1.19 & 1.923 & 4.89 \\
\hline $5-10$ years & 0.564 & -3.10 & 0.899 & -0.26 & 1.793 & 3.04 \\
\hline$>10$ years & 0.456 & -4.80 & 0.770 & -1.35 & 1.482 & 2.19 \\
\hline $\mathrm{N}$ & \multirow{3}{*}{\multicolumn{2}{|c|}{28.93}} & \multicolumn{2}{|c|}{4,905} & \multirow{3}{*}{\multicolumn{2}{|c|}{31.42}} \\
\hline Distribution (\%) & & & \multirow{2}{*}{\multicolumn{2}{|c|}{$\begin{array}{c}21.04 \\
-6,322\end{array}$}} & & \\
\hline Log Likelihood & & & & & & \\
\hline
\end{tabular}

RRR: Relative risk ratios.

$\mathrm{y}=0$ : The individual is not mismatched in any wave.

$\mathrm{y}=1$ : The individual is mismatched in 1 wave.

$\mathrm{y}=2$ : The individual is mismatched in 2 waves (consecutive or not).

$\mathrm{y}=3$ : The individual is mismatched in 3 waves or more (consecutive or not).

The most significant differences among the two definitions are those concerning educational attainments. For both types we find that 
educational level exerts a strong influence on the probability of experiencing an educational mismatch of either one, two, or more than two years. Nonetheless, the difference is in the sign of the estimated coefficients of the educational variables. People who have completed higher secondary and university education are less likely to exhibit an educational mismatch in a broad sense, and this effect increases when mismatched for two or more than two waves. These results are coherent assuming that mismatch type B potentially includes under-education, a job-quality problem which usually affects workers with lower educational levels. The opposite is observed for over-qualification (type A), but the increasing pattern of this effect is even more important than for the previous definition of mismatch.

Our results also reveal different effects of on-the-job training on the probability of experiencing an educational mismatch, based on the definition we use. Individuals receiving on-the-job training, provided by the employer, are less likely to experience a mismatch type B (mismatch including under-education), for either one or more than two years. However, while receiving on-the-job training does not affect the probability of being over-educated during one year, it does increase the probability of experiencing a mismatch type A (over-qualification) for two, or more than two years. The latter contradicts previous results in the literature that view over-education as a compensation for a lack of experience or of other human capital endowments, such as ability or onthe-job training (see Groot, 1993, 1996; Sicherman, 1991; Alba-Ramirez, 1993).

Individuals working in the public sector have a lower probability of being mismatched type $\mathrm{B}$ (mismatch including under-education). In contrast, the estimated coefficients of this explanatory variable are not statistically significant when mismatch type A definition (overqualification) is used.

Finally, the estimation results reveal a negative and significant influence of seniority on the likelihood of being mismatched type A (overeducated) for one year. However, independent of the mismatch definition, the estimations show a positive and significant influence of seniority on the probability of being mismatched for three or more than three years.

The second part of this section concerns the relationship between educational mismatch and mobility. Special attention is given to the incidence of being a person with disabilities on both the probability of getting a better match and job mobility. 
Table 4. Multinomial logit model on the probability of having educational mismatch in a broad sense (mismatch type B). ECHP 1995-2000 (Spain).

\begin{tabular}{|c|c|c|c|c|c|c|}
\hline \multirow{3}{*}{ Variable } & \multirow{2}{*}{$\ln \left[\frac{1}{\mathrm{~F}}\right.$} & \multirow{2}{*}{$\frac{\operatorname{Pr}(y=1)}{\operatorname{Pr}(y=0)}$} & \multirow{2}{*}{$\ln \frac{\mathrm{P}}{\mathrm{P}}$} & \multirow{2}{*}{$\frac{\operatorname{Pr}(y=2)}{\operatorname{Pr}(y=0)}$} & \multirow{2}{*}{$\ln \left[\frac{P}{P}\right.$} & \multirow{2}{*}{$\frac{\operatorname{Pr}(y=3)}{\operatorname{Pr}(y=0)}$} \\
\hline & & & & & & \\
\hline & RRR & $\mathrm{t}$ & RRR & $\mathrm{T}$ & RRR & $\mathrm{t}$ \\
\hline Male & 1.158 & 1.54 & 1.389 & 2.92 & 1.533 & 4.03 \\
\hline Married & 1.105 & 0.63 & 1.077 & 0.64 & 1.488 & 3.12 \\
\hline Age & 0.997 & 0.02 & 1.079 & 1.96 & 1.127 & 3.38 \\
\hline $\mathrm{Age}^{2}$ & 1.000 & 0.04 & 0.999 & -2.21 & 0.998 & -4.27 \\
\hline \multicolumn{7}{|l|}{ Educational Level } \\
\hline Primary & - & - & - & - & - & - \\
\hline Secondary & 0.352 & -7.77 & 0.338 & -7.26 & 0.252 & -9.80 \\
\hline University & 0.232 & -10.42 & 0.140 & -11.81 & 0.113 & -14.56 \\
\hline Training & 0.647 & -3.94 & 0.893 & -0.77 & 0.718 & -2.71 \\
\hline Open-ended contract & 0.717 & -2.59 & 1.041 & 0.41 & 1.180 & 1.31 \\
\hline Disability & 1.158 & 0.50 & 1.428 & 1.22 & 0.789 & -0.83 \\
\hline \multicolumn{7}{|l|}{ Type of Firm } \\
\hline Pub. Adm./Pub. Firm & 0.729 & -2.32 & 0.647 & -2.80 & 0.781 & -1.73 \\
\hline Private (<20 workers) & - & - & - & - & - & - \\
\hline Private $(20-500 \mathrm{w})$. & 0.967 & -0.24 & 0.921 & -0.60 & 1.015 & 0.23 \\
\hline Private (>500 w.) & 1.437 & 2.03 & 1.073 & 0.30 & 1.566 & 2.30 \\
\hline \multicolumn{7}{|l|}{ Seniority } \\
\hline$<1$ year & - & - & - & - & - & - \\
\hline $1-5$ years & 1.329 & 2.22 & 1.414 & 2.36 & 2.494 & 6.59 \\
\hline 5 -10 years & 0.905 & -0.62 & 0.892 & -0.60 & 1.553 & 2.27 \\
\hline$>10$ years & 0.924 & -0.36 & 0.980 & -0.09 & 1.838 & 3.25 \\
\hline $\mathrm{N}$ & \multirow{3}{*}{\multicolumn{2}{|c|}{28.57}} & \multicolumn{2}{|c|}{5,016} & \multirow{3}{*}{\multicolumn{2}{|c|}{29.98}} \\
\hline Distribution (\%) & & & & & & \\
\hline Log Likelihood & & & & & & \\
\hline
\end{tabular}

RRR: Relative risk ratios.

$\mathrm{y}=0$ : The individual is not mismatched in any wave.

$y=1$ : The individual is mismatched in 1 wave.

$\mathrm{y}=2$ : The individual is mismatched in 2 waves (consecutive or not).

$y=3$ : The individual is mismatched in 3 waves or more (consecutive or not).

In order to analyse the determinants affecting the probability of getting a better match, we estimate a multinomial logit model. The sample selected for this analysis is composed of wage and salary workers aged between 16 and 65 years old, who are mismatched the first time they are interviewed. The dependent variable takes value 0 if the individual remains mismatched over the rest of the interviews, 1 if the individual gets a better match at any time over the following interviews, and 2 if the 
individual moves to other situations ${ }^{13}$. The results of these estimations are reported in Table 5. Our main interest is in the estimated coefficient for the dummy variable indicating whether the individual is a person with or without disabilities. We can see that people with disabilities are less likely to get a better match while being more likely to move towards other situations (inactivity or marginal employment) when we use the definition of mismatch in a broad sense (type B). In contrast, when we use the variable for over-education (mismatch type A definition), we do not observe people with disabilities as being more or less likely to improve their job match, but we still observe this group as having a higher probability of moving towards other situations ${ }^{14}$. Thus, when starting from a situation of skill-mismatch, people with disabilities seem to experience a weaker position in the labour market, since they have a lower probability of leaving that situation towards a better match, and a higher probability of moving towards unemployment or inactivity.

As regards the remaining explanatory variables, some points are worth mentioning. First, we observe that for mismatch type A (overqualification) and B (mismatch in a broad sense), receiving on-the-job training and holding a permanent contract reduces the probability of moving towards other situations, although a permanent contract increases the probability of leaving mismatch towards a better match using the broad definition of mismatch (type B). Second, our results show that the estimated coefficients of the educational variables are not statistically significant for mismatch including under-education (type B). Nonetheless, we observe that people who have completed higher secondary and university education are less likely to get a better match for overqualification (type A). This result is consistent with those obtained from the multinomial logit estimation, reported in Table 3, where we observed an increasing coefficient for these explanatory variables with the persistence of educational mismatch. For both definitions we find evidence of people working in the public sector and in private firms with more than 20 employees as being less likely to move towards inactivity or marginal employment. We also find a negative and significant influence of seniority on the probability of moving towards inactivity or marginal employment.

\footnotetext{
13 Other situations include self-employment, unpaid family work, jobs of fewer than 15 hours per week, unemployed and economically inactive workers.

14 For both definitions, when we exclude economically inactive workers from the nonemployment category, we do not observe people with disabilities being more likely to move towards a non-employment situation.
} 
Table 5. Multinomial logit model on the probability of leaving over-education. ECHP 1995-2000 (Spain).

\begin{tabular}{|c|c|c|c|c|c|c|c|c|}
\hline \multirow[t]{3}{*}{ Variable } & \multicolumn{4}{|c|}{ Mismatch Type A } & \multicolumn{4}{|c|}{ Mismatch Type B } \\
\hline & \multirow{2}{*}{$\ln [$} & \multirow{2}{*}{$\frac{\operatorname{Pr}(z=1)}{\operatorname{Pr}(z=0)}$} & \multirow{2}{*}{\multicolumn{2}{|c|}{$\frac{\operatorname{Pr}(z=2)}{\operatorname{Pr}(z=0)}$}} & \multirow{2}{*}{$\ln \left[\frac{1}{\mathrm{~F}}\right.$} & \multirow{2}{*}{$\left.\frac{\operatorname{Pr}(z=1)}{\operatorname{Pr}(z=0)}\right]$} & \multirow{2}{*}{$\ln \left[\frac{\mathrm{P}}{\mathrm{P}}\right.$} & \multirow{2}{*}{$\frac{\operatorname{Pr}(z=2)}{\operatorname{Pr}(z=0)}$} \\
\hline & & & & & & & & \\
\hline & RRR & $\mathrm{t}$ & RRR. & $\mathrm{t}$ & RRR & $\mathrm{t}$ & RRR & $\mathrm{T}$ \\
\hline Male & 0.645 & -3.49 & 0.610 & -3.37 & 1.006 & 0.05 & 0.727 & -2.33 \\
\hline Married & 1.175 & 1.16 & 1.190 & 1.04 & 0.965 & -0.25 & 1.139 & 0.84 \\
\hline Age & 1.110 & 2.34 & 0.940 & -1.33 & 1.049 & 1.18 & 0.831 & -4.66 \\
\hline $\mathrm{Age}^{2}$ & 0.999 & -1.49 & 1.001 & 2.39 & 0.999 & -0.12 & 1.002 & 5.67 \\
\hline \multicolumn{9}{|l|}{ Educ. Level } \\
\hline Primary & - & - & - & - & - & - & - & - \\
\hline Secondary & 0.580 & -3.48 & 0.967 & -0.19 & 1.142 & 0.88 & 1.321 & 1.69 \\
\hline University & 0.349 & -5.86 & 0.539 & -2.95 & 1.045 & 0.23 & 0.950 & -0.21 \\
\hline Training & 0.898 & -0.85 & 0.518 & -3.95 & 1.285 & 1.81 & 0.623 & -2.43 \\
\hline Open-ended contract & 0.808 & -1.24 & 0.431 & -4.57 & 1.399 & 2.07 & 0.485 & -4.40 \\
\hline Disability & 1.332 & 0.72 & 2.218 & 1.94 & 0.380 & -3.22 & 1.820 & 2.43 \\
\hline \multicolumn{9}{|l|}{ Type of Firm } \\
\hline Pub. Adm. and Pub. Firm & 0.728 & -1.92 & 0.439 & -4.16 & 0.905 & -0.61 & 0.328 & -5.26 \\
\hline Private (<20 workers) & - & - & - & - & - & - & - & - \\
\hline Private $(20-500 \mathrm{w})$. & 0.783 & -1.59 & 0.521 & -3.95 & 1.055 & 0.40 & 0.554 & -4.16 \\
\hline Private (>500 w.) & 0.694 & -1.69 & 0.476 & -2.70 & 1.129 & 0.60 & 0.605 & -1.95 \\
\hline \multicolumn{9}{|l|}{ Seniority } \\
\hline$<1$ year & - & - & - & - & - & - & - & - \\
\hline $1-5$ years & 1.009 & 0.05 & 0.684 & -2.07 & 0.905 & -0.52 & 0.745 & -1.83 \\
\hline $5-10$ years & 0.919 & -0.34 & 0.523 & -2.43 & 0.863 & -0.62 & 0.401 & -3.70 \\
\hline$>10$ years & 1.274 & 0.96 & 0.458 & -2.84 & 0.724 & -1.36 & 0.382 & -4.04 \\
\hline $\mathrm{N}$ & \multicolumn{4}{|c|}{1,906} & \multicolumn{4}{|c|}{2,076} \\
\hline Distribution (\%) & \multicolumn{2}{|c|}{36.62} & \multicolumn{2}{|c|}{23.56} & \multirow{2}{*}{\multicolumn{2}{|c|}{35.89}} & \multirow{2}{*}{\multicolumn{2}{|c|}{28.03}} \\
\hline Log Likelihood & & & & & & & & \\
\hline
\end{tabular}

RRR: Relative risk ratios.

Sample: Wage and salary workers who are mismatched the first time they are interviewed. $\mathrm{z}=0$ : The individual does not leave his/her mismatch.

$\mathrm{z}=1$ : The individual leaves his/her mismatch for a better match.

$\mathrm{z}=2$ : The individual leaves his/her mismatch for other situations.

'Other situation' means self-employment, unpaid family work, jobs of less than 15 hours per week, unemployed and economically inactive workers

Finally, we analyse the influence of disability and educational mismatch on job mobility in general. A multinomial logit model is used to model the transition probabilities from job to job ${ }^{15}$ or other situations. Both demand-and supply-side factors influence the transition probabilities. Therefore, the estimated multinomial logit model can be

15 Here, job-to-job indicates that the individual is working in different waves of the survey, although it is possible that some individuals will have non-observed unemployment or inactivity periods between both jobs. 
regarded as a reduced form model capturing the combined effect of both types of factors. A broad set of explanatory variables including individual and job-related characteristics is used. The individual characteristics are: sex, marital status, age and its square, maximum level of educational attainments, and a dummy variable indicating whether the individual is a person with or without disabilities. The job-related characteristics include: type of contract, on-the-job training, type of firm, seniority, a dummy variable indicating whether the individual is mismatched or not, and a set of occupational dummy variables. The results of this estimation are reported in Table 6. Our main interest is in the estimated coefficients of the dummy variable indicating whether the individual is a person with or without disabilities, and in the dummy variable indicating whether the individual is mismatched. With respect to the first variable, we do not observe people with disabilities experiencing either a higher or lower probability of changing job. Nonetheless, the results reveal that this group of people is more likely to move towards other situations, although the effect disappears when excluding economically inactive workers from the 'other situations' category. As regards the effects of being mismatched on job mobility, we find that the estimated coefficient of this variable is not statistically significant when using mismatch including under-education (type B definition). Nonetheless, for over-qualification (mismatch type A), the results provide evidence in favour of the hypothesis that mismatched workers are more likely to change jobs.

Regarding the rest of variables, we see that the educational level is only important for mobility to other situations (a university degree decreases the probability of this transition in Table 6). As predicted by jobmatching theory, we find a negative effect of seniority on external job mobility. Moreover, our results support the predictions of human capital and job-matching theories in the sense that workers receiving on-the-job training are less likely to exhibit external job mobility.

All types of firms have a lower mobility with respect to being in a private firm with fewer than 20 workers, the exception being a private firm with between 20 to 500 workers, which is nonsignificant for job-to-job mobility. Gender is barely significant, but the sign is as it was expected: being male increases the probability of job-to-job mobility but decreases the probability of moving towards other situations. Being married does not affect job mobility. Finally, age has a non-linear influence on both types of mobility and it decreases mobility, but at a decreasing rate. 
Table 6. Multinomial logit model on the probability of employment mobility. ECHP 1995-2000 (Spain).

\begin{tabular}{|c|c|c|c|c|c|c|c|c|}
\hline \multirow[t]{3}{*}{ Variable } & \multicolumn{4}{|c|}{ Mismatch Type A } & \multicolumn{4}{|c|}{ Mismatch Type B } \\
\hline & \multirow{2}{*}{$\ln \left[\frac{\mathrm{F}}{\mathrm{P}}\right.$} & \multirow{2}{*}{$\frac{\operatorname{Pr}(x=1)}{\operatorname{Pr}(x=0)}$} & \multirow{2}{*}{$\ln \left[\frac{\mathrm{P}}{\mathrm{P}}\right.$} & \multirow{2}{*}{$\left.\frac{\operatorname{Pr}(x=2)}{\operatorname{Pr}(x=0)}\right]$} & \multirow{2}{*}{$\ln \left[\frac{\mathrm{Pl}}{\mathrm{Pr}}\right.$} & \multirow{2}{*}{$\frac{\operatorname{Pr}(x=1)}{\operatorname{Pr}(x=0)}$} & \multirow{2}{*}{$\ln \left[\frac{\mathrm{P}}{\mathrm{P}}\right.$} & \multirow{2}{*}{$\frac{\operatorname{Pr}(x=2)}{\operatorname{Pr}(x=0)}$} \\
\hline & & & & & & & & \\
\hline & RRR & $\mathrm{t}$ & RRR. & $\mathrm{t}$ & RRR & $\mathrm{t}$ & RRR & $\mathrm{t}$ \\
\hline Male & 1.184 & 1.67 & 0.838 & -1.89 & 1.194 & 1.75 & 0.842 & -1.85 \\
\hline Married & 1.124 & 0.90 & 1.157 & 1.36 & 1.111 & 0.79 & 1.151 & 1.31 \\
\hline Age & 0.919 & -2.39 & 0.808 & -7.78 & 0.927 & -2.19 & 0.809 & -7.75 \\
\hline $\mathrm{Age}^{2}$ & 1.001 & 2.25 & 1.003 & 9.31 & 1.000 & 2.02 & 1.003 & 9.27 \\
\hline \multicolumn{9}{|l|}{ Educational Level } \\
\hline Primary & - & - & - & - & - & - & - & - \\
\hline Secondary & 0.939 & -0.54 & 1.022 & 0.19 & 1.020 & 0.07 & 1.062 & 0.51 \\
\hline University & 0.815 & -1.32 & 0.588 & -3.85 & 0.884 & -0.76 & 0.619 & -3.47 \\
\hline Training & 0.546 & -4.61 & 0.550 & -5.29 & 0.553 & -4.53 & 0.555 & -5.22 \\
\hline Open-ended contract & 0.239 & -11.45 & 0.343 & -9.87 & 0.238 & -11.51 & 0.342 & -9.89 \\
\hline Disability & 1.425 & 1.42 & 1.793 & 3.11 & 1.377 & 1.29 & 1.771 & 3.05 \\
\hline \multicolumn{9}{|l|}{ Type of Firm } \\
\hline Pub. Adm. And Pub. Firm & 0.467 & -5.02 & 0.378 & -7.80 & 0.461 & -5.11 & 0.377 & -7.79 \\
\hline Private (<20 workers) & - & - & - & - & - & - & - & - \\
\hline Private (20-500 w.) & 0.874 & -1.25 & 0.554 & -5.90 & 0.887 & -1.12 & 0.556 & -5.87 \\
\hline Private (>500 w.) & 0.821 & -0.90 & 0.567 & -3.55 & 0.821 & -0.91 & 0.562 & -3.60 \\
\hline \multicolumn{9}{|l|}{ Seniority } \\
\hline$<1$ year & - & - & - & - & - & - & - & - \\
\hline $1-5$ years & 0.753 & -2.45 & 0.817 & -1.86 & 0.740 & -2.61 & 0.812 & -1.93 \\
\hline $5-10$ years & 0.454 & -4.49 & 0.423 & -5.07 & 0.451 & -4.54 & 0.422 & -5.08 \\
\hline$>10$ years & 0.158 & -8.86 & 0.343 & -6.76 & 0.152 & -9.05 & 0.339 & -6.82 \\
\hline Mismatch & 1.425 & 3.29 & 1.161 & 1.54 & 0.947 & -0.31 & 1.046 & 0.54 \\
\hline $\mathrm{N}$ & \multicolumn{4}{|c|}{4,467} & \multicolumn{4}{|c|}{4,472} \\
\hline Distribution (\%) & \multicolumn{2}{|c|}{17.98} & \multirow{2}{*}{\multicolumn{2}{|c|}{26.86}} & \multirow{2}{*}{\multicolumn{2}{|c|}{18.00}} & \multirow{2}{*}{\multicolumn{2}{|c|}{26.86}} \\
\hline Log Likelihood & & & & & & & & \\
\hline
\end{tabular}

RRR: Relative risk ratios.

$\mathrm{x}=0$ : The individual does not move from his/her job.

$\mathrm{x}=1$ : The individual leaves his/her job to get another job.

$\mathrm{x}=2$ : The individual leaves his/her job to go to other situations.

'Other situation' means self-employment, unpaid family work, jobs of less than 15 hours per week, unemployed and economically inactive workers

To sum up, we have seen that educational mismatch is not necessarily a typical feature of disadvantaged groups in the labour market, In the case of people with disabilities, disadvantage takes the form of a higher mobility towards inactivity or marginal employment (even when leaving mismatch). 


\section{Conclusions}

In this article, we have analysed the quality of the job match of people with disabilities in terms of their educational mismatch. As they are a disadvantaged group in the labour market, we expect that they suffer higher levels of mismatch than other disadvantaged groups such as ethnic minorities or women (Battu and Sloane, 2002; Frank, 1978). Using Spanish longitudinal data from the ECHP covering the period 1995-2000, we define two measures of mismatch for the empirical analysis: overqualification and mismatch in a broad sense (including under-education). The results concerning people with disabilities are broadly the same with each of the two definitions of mismatch.

First of all, the descriptive analysis shows that people with disabilities have a lower proportion of over-education or over-qualification but a higher proportion of mismatch in a broad sense. However, we do not find a significant influence of disability on the probability of being mismatched; with the exception of a negative effect on the probability of being mismatched for more than three waves using the definition of overeducation (mismatch type A). Of course this result does not imply the nonexistence of wage discrimination or absence of discrimination in the hiring process. In fact, wage discrimination for people with disabilities has been previously documented, and the huge difference between the participation rates of people with and without disabilities can be attributed, at least partially, to discrimination (see, for example, Baldwin and Johnson, 1995, and Kidd et al., 2000). Our results suggest that when people with disabilities get a job they do not have a higher probability of suffering mismatch because of their disabilities. However, when people with disabilities are mismatched they leave their mismatch with a lower probability in a broad sense (type B), unless they move to non-employment or marginal employment. This last result reveals the weak position of this group in the labour market. Therefore, our results show that disadvantaged groups will not always have a higher mismatch, providing a richer variety of results than those previously obtained in the literature on mismatch. Furthermore, additional improvements of the educational level of people with disabilities are not subject to the risk of over-education considering the typically lower educational level of this group and, in general, their lower probability of being mismatched. Finally, considering that previous results have documented the relatively high educational returns for people with disabilities (see Dean and Dolan, 1992, and Hendricks et al., 1997) the promotion of education among people with 
disabilities seems to be a promising way to improve the position of this group in the labour market.

\section{References}

Alba-Ramírez, A. (1993), "Mismatch in the Spanish Labor Market. Overeducation?", Journal of Human Resources, 28 (2), 259-278.

Alba-Ramírez, A. and Blázquez, M. (2004): "Types of Job Match, Overeducation, and Labour Mobility in Spain”, in F. Büchel, A. de Grip, A. and A. Mertens, (eds.), Overeducation in Europe: Current issues in theory and policy. Cheltenham, UK: Edward Elgar.

Baldwin, M.L. and Johnson, W.G. (1995): "Labor Market Discrimination against Women with Disabilities", Industrial Relations, vol. 34 (4), 555577.

Battu, H. and Sloane, P.J. (2002): "To what extent are ethnic minorities in Britain over-educated?", International Journal of Manpower, vol. 23 (3), 192-208.

Cohn, E. and S. Kahn (1995): “The Wage Effects of Overschooling Revisted", Labour Economics, 2, 67-76.

Dean, D.H. and Dolan, R.C. (1992): "Efficacy of Higher Education for Persons with Work Disabilities", Economics of Education Review, vol. 11 (1), 51-60.

Duncan, G. and S. Hoffman (1981): "The Incidence and Wage Effects of Overeducation", Economics of Education Review, 1, 75-86.

Frank, R.H. (1978): "Why Women Earn Less: The Theory and Estimation of Differential Overqualification”, American Economic Review, vol. 68 (3), 360-373.

Freeman, R. (1976), The Overeducated American, New York, Academic Press.

García-Serrano, C. and Malo, M.A. (1996): "Desajuste educativo y movilidad laboral en España”, Revista de Economía Aplicada, 11, 105-131. 
García-Serrano, C. and Malo, M.A. (2002): "Discapacidad y mercado de trabajo en la Unión Europea", Cuadernos Aragoneses de Economía, vol. 12 (2), 237-255.

Groot, W. (1993): "Overeducation and the Returns to Enterprise-related Schooling", Economics of Education Review, 12, 299-309.

Groot, W. (1996): "The Incidence of, and Returns to Overeducation in the UK”, Applied Economics, 28, 1345-1350.

Groot, W. and H. Maassen van den Brink (1997): "Allocation and the Returns to Overeducation in the United Kingdom", Education Economics, $5,169-183$

Hartog, J. and H. Oosterbeek (1988): "Education, Allocation and Earnings in the Netherlands; Overschooling?", Economics of Education Review, 7, 185-194.

Hendricks, W., Schiro-Geist, C. and Broadbent, E. (1997): "Long-Term Disabilities and College Education”, Industrial Relations, vol. 36 (1), 4660 .

Jovanovic, B. (1979): "Job Matching and the Theory of Turnover", Journal of Political Economy, 87, 972-990.

Kidd, M.P., Sloane, P.J., y Ferko, I. (2000): "Disability and the Labour Market: An Analysis of British Males", Journal of Health Economics, 19, pp. 961-981.

Malo, M.A. (2003): "Las personas con discapacidad en el mercado de trabajo español", Revista del Ministerio de Trabajo y Asuntos Sociales, Economía y Sociología, 46, 99-126.

McGoldrick, K. and Robst, J. (1996): "Gender Differences in Overeducation: A Test of the Theory of Differential Overqualification", American Economic Review, Papers and Proceedings, vol. 8(2), 280-284.

Oi, W. (1991): "Disability and a Workfare-Welfare Dilemma", en C. Weaver (ed.), Disability and Work, AEI Press, Washington.

Roqueta Buj, R. (2000). La Incapacidad Permanente. Consejo Económico y Social. Colección Estudios, Madrid. 
Rosen, S. (1972): "Learning and Experience in the Labour Market", Journal of Human Resources, 7, 326-342.

Rumberger, R. (1987): "The Impact of Surplus Schooling on Productivity and Earnings". Journal of Human Resources, 22(1), 24-50.

Sánchez-Cervera, J.M. and Sánchez-Cervera, J.M. (2000): Los trabajadores discapacitados. Contratación, incentivos, centros especiales de empleo, prestaciones sociales, fiscalidad, Editorial CISS, Valencia.

Sicherman, N. (1991): "Overeducation in the Labor Market", Journal of Labor Economics, vol. 9 (2), 101-122.

Sicherman, N. and O. Galor (1990): "A Theory of Career Mobility", Journal of Political Economy, 98, 160-192.

Sloane, P.J. (2004): "Much Ado About Nothing? What Does the OverEducation Literature Really Tell Us?", in F. Büchel, A. de Grip, A. and A. Mertens, (eds.), Overeducation in Europe: Current issues in theory and policy. Cheltenham, UK: Edward Elgar.

Spence, M. (1973): "Job Market Signalling”, Quarterly Journal of Economics, 87, 355-374.

Thurow, L. (1975): Generating Inequality: Mechanisms of Distribution in the U.S Economy, New York, Basic Books.

Thurow, L.C and Lucas, R.E.B (1972): The American Distribution on Income: A Structural Problem. A Study for the Joint Economic Committee, U.S Congress, U.S Government. Printing Office, Washington.

Verdugo, R. and N. Verdugo (1989): "The Impact of Surplus Schooling on Earnings: Some Additional Findings", Journal of Resources, 24, 629-643. 
Zwinkels, W. (2001): "The employment situation of people with disabilities in the European Union”, EIM Business and Policy Research. 